\title{
Full-field characterisation of crack tip deformation and fatigue crack growth using Digital Image Correlation - A review
}

\author{
J. Tong ${ }^{*}$ \\ *Mechanical Behaviour of Materials Laboratory, School of Engineering, \\ University of Portsmouth, UK \\ jie.tong@port.ac.uk
}

\begin{abstract}
In recent years, Digital Image Correlation (DIC) has been widely used in the analysis of crack problems. This review will examine DIC, as a full-field measurement technique, in the studies of crack tip mechanical behavior under cyclic loading conditions. In particular, topics including determination of fracture mechanics parameters and evaluation of crack closure will be discussed. Micromechanical aspects of crack growth under cyclic loading will also be explored in terms of crack driving and attenuation effects.
\end{abstract}

\section{INTRODUCTION}

Quantifying fatigue crack growth is of great importance in the damage tolerance assessment of fracture-critical engineering components and structures. The first significant event in the history of fatigue crack growth characterisation is the use of stress intensity factor range $\Delta \mathrm{K}$ to correlate fatigue crack growth rates, by Paris et $a l,{ }^{1}$ based on three independent studies. Rice $^{2}$ further rationalised this approach within the framework of continuum mechanics, suggested that fatigue crack growth rate data may be correlated by a stress intensity factor range. It has since been widely accepted that the use of an elastic stress intensity factor range, $\Delta \mathrm{K}$, is adequate in most of the engineering applications under small scale yielding (SSY) conditions, although the role of load ratio $R$ was also recognised around the same time, ${ }^{3}$ which was subsequently rationalised through the consideration of a concept of "crack closure", a phenomenon first reported by Elber, ${ }^{4}$ who observed that a crack may be partially closed when subjected to cyclic tensile loads.

This marks the second significant event in the history of fatigue crack characterisation, where an "effective" stress intensity factor, $\Delta K_{\text {eff, }}$ is recommended to replace $\Delta K$. A general feature of crack closure ${ }^{5}$ is a change of stiffness in the load against displacement curves, marked by a "knee" in the measured compliance curves during loading and unloading, which is considered to be indicative of "crack opening", from which $K_{\text {op }}$ may be estimated and an "effective" stress intensity factor $\Delta \mathrm{K}_{\text {eff }}\left(\mathrm{K}_{\max }-\mathrm{K}_{\mathrm{op}}\right)$ may be obtained. Since $\mathrm{K}_{\mathrm{op}}$ is usually larger than $\mathrm{K}_{\min }$ for tension-tension cycles at low load ratios, $\Delta \mathrm{K}_{\text {eff }}$ is usually smaller than the applied $\Delta \mathrm{K}$. Considerable research has since been carried out to utilise the concept of crack closure to rationalise a wide range of fatigue crack growth data, with an estimated some 10,000 papers published $^{6}$ since Elber. ${ }^{4}$ Of the main types of crack closure, ${ }^{5,6}$ plasticity-induced crack closure has been used as the default interpretation of load ratio effects, and is incorporated in some fatigue life prediction models. A comprehensive review on the topic is given in Pippan and Hohenwarter. ${ }^{6}$ Despite of some doubts ${ }^{7}$ expressed on the role of crack closure in regulating crack driving force or fatigue crack growth rates, systematic studies of fatigue crack problems 
were not possible till recently, due to the lack of suitable experimental tools to extract fullfield information around a crack tip in situ. This obstacle has now been overcome due to the availability and popularity of high resolution full-field measurement tools such as Digital Image Correlation (DIC).

From a material science perspective, fatigue crack propagation behaviour of materials has been considered through "intrinsic" and "extrinsic" mechanisms, ${ }^{11}$ where "intrinsic" mechanisms concern with the formation of new fracture surfaces; whilst "extrinsic" mechanisms consider "shielding" effects, notably due to various mechanisms of crack closure. From an engineering point of view, fatigue crack growth may be considered as primary events occurring ahead of the crack tip and secondary events occurring behind the crack tip, as illustrated in Fig. 1. Although ample evidence indicates the presence of both primary and secondary events around a fatigue crack tip, the roles of these events in fatigue crack growth process are not well defined. In particular, how do secondary events such as crack closure or "shielding" affect primary events ahead of the crack tip is a fundamental unknown, a challenge to study due to the lack of tools for direct experimental measurement and observation in the past. At a local level, for crack growth to occur, the material ahead of the crack tip must separate, hence a local mechanical driving force should be of significant interest. However, although mechanisms for material separation in various material systems have been studied in some detail, the progress towards a quantitative measure ${ }^{2}$ of microcrack driving force for fatigue crack growth is still lacking. With the advance of the DIC techniques, together with scanning electron microscopy (SEM), the interactions between strain evolution, microstructure and fatigue crack growth behaviour may be studied at subgrain level for the first time.

This review will summarise some of the notable contributions towards the characterisation of crack tip field using the DIC method. The task has benefited from the author's participation of a series of joint IJF and FFEMS workshops on Characterisation of Crack Tip Fields; and I am grateful for the invitation of the editor-in-Chief, Professor YS Hong of FFEMS, to prepare this review. The review aims to discuss the following aspects: i) Parameter selection and measurement uncertainty in DIC application to crack problems; ii) determination of fracture mechanics parameters using DIC; iii) evaluation of crack closure and its impact on crack driving force; iv) micro-mechanics characterisation of crack tip field.

\section{BASIC PRINCIPLES OF DIGITAL IMAGE CORRELATION (DIC)}

The basic principle of DIC is to correlate two digital images taken from a specimen surface before and after deformation. The first image is taken as the reference image and the second one as the deformed image. Random speckle patterns are created on the surface of the specimen, so that a small region of the specimen in the reference image is tracked to the same region in the deformed image. The small region consisting of pixels (at least $3 \times 3$ pixels ${ }^{2}$ ) with varied gray scales is named a subset. By comparing the digital images of subsets throughout the images before and after deformation, mathematical mapping and cross correlation are carried out, and the displacement fields in the target region are obtained by minimising the correlation coefficient. 
Fig. 2 illustrates the basic principle of DIC. Assuming that a point $(x, y)$ in the reference image is mapped onto a point $\left(x^{*}, y^{*}\right)$ in the deformed image. The mapping can be performed as:

$$
\begin{aligned}
& x^{*}=x+u(x, y) \\
& y^{*}=y+v(x, y)
\end{aligned}
$$

Displacements $u$ and $v$ may be approximated using Taylor series:

$$
\begin{aligned}
& x^{*}=x+u+\frac{\partial u}{\partial x} \Delta x+\frac{\partial u}{\partial y} \Delta y+\frac{1}{2} \frac{\partial^{2} u}{\partial x^{2}} \Delta x^{2}+\frac{1}{2} \frac{\partial^{2} u}{\partial y^{2}} \Delta y^{2}+\frac{\partial^{2} u}{\partial x \partial y} \Delta x \Delta y \\
& y^{*}=y+v+\frac{\partial v}{\partial x} \Delta x+\frac{\partial v}{\partial y} \Delta y+\frac{1}{2} \frac{\partial^{2} v}{\partial x^{2}} \Delta x^{2}+\frac{1}{2} \frac{\partial^{2} v}{\partial y^{2}} \Delta y^{2}+\frac{\partial^{2} v}{\partial x \partial y} \Delta x \Delta y
\end{aligned}
$$

where $u$ and $v$ are the translations of the center of the sub-image in the $X$ and $Y$ directions, respectively. The distances from the center of the sub-image to the point $(\mathrm{x}, \mathrm{y})$ are denoted by $\Delta x$ and $\Delta y$. DIC relies on finding the maximum of the correlation array between pixel intensity array subsets of the two corresponding images. A correlation coefficient $\mathrm{C}$ may be defined:

$$
C=\frac{\sum_{S} f(x, y) g\left(x^{*}, y^{*}\right)}{\sqrt{\sum_{S} f^{2}(x, y) \sum_{S} g^{2}\left(x^{*}, y^{*}\right)}}
$$

Where $f(x, y)$ is the gray-scale value at a point $(x, y)$ in the reference image, $g\left(x^{*}, y^{*}\right)$ is the gray-scale value at a point $\left(x^{*}, y^{*}\right)$ in the deformed image and $S$ is subset. Hence the correlation coefficient $C$ is a function of displacement components $(u, v)$ and displacement gradients. In practice, Fast Fourier Transformation (FFT) is often used for computation of the cross correlation.

Sutton and his associates ${ }^{8,9}$ were the first to utilise DIC in the studies of fatigue and fracture problems, and they obtained crack opening displacements post fatigue testing and image acquisition, and estimated stress intensity factor for selected specimen geometries. ${ }^{10}$ Although DIC is limited to surface measurements, the speckle patterns may be generated by a number of methods and can be artificially manipulated to obtain the desired spatial resolution. This is more advantageous in achieving high resolution measurements near a crack tip, compared with other 3D measurement techniques such as digital volume correlation (DVC), where spatial resolution relies on inherent textual markers most metallic materials lack. Generally, bulk measurements of metallic specimens often require more specialist tools such as synchrotron X-ray tomography and diffraction which are not readily available. Unless otherwise stated, this review will be focused on full-field measurements using DIC.

\section{PARAMETER SELECTION AND MEASUREMENT UNCERTAINTIES}

As an optical approach, DIC is subject to a variety of errors, both random and systematic, which may arise during the processes of image acquisition and correlation analysis. Within the context of solid mechanics, sources of errors may include speckle patterns, ${ }^{12-16}$ subset shape function, ${ }^{12,17}$ subset size ${ }^{18,19}$ and sub-pixel registration and correlation algorithms, ${ }^{12,17}$ 
although a detailed discussion on measurement uncertainties is beyond the scope of this review. In the early days of application of DIC method to crack problems, few discussed the strategies of parameter selection or measurement uncertainties. More recently, published work $^{20-26}$ have paid more attention to these issues, recognising the critical importance of parameter selection in the measurement of full-field displacements and strains in the presence of a crack, where displacement discontinuity, high strain gradients and non-linear deformation prevail near a crack tip.

Measurement uncertainties in displacements and strains have been assessed using artificial manipulations of images, ${ }^{20}$ where an artificial image is constructed from the reference image by a sub-pixel translation. The correlation algorithm is applied to both images allowing an evaluation of measurement uncertainty. Most work to date have focused on the estimation of stress intensity factor (SIF) using the displacement data extracted from DIC images, ${ }^{10,20-26}$ although not all reported the strategies for parameter selection or measurement uncertainties. A range of field of view (FOV) was used (from $2 \times 2 \mathrm{~mm}^{2}$ to $18 \times 24 \mathrm{~mm}^{2}$ ), with a portion of crack normally included. Roux and $\mathrm{Hild}^{20}$ studied displacement and strain uncertainties of a cracked specimen using two different measurement and identification routes, and they found that the uncertainties associated with the measured displacements $(0.4 \sigma(\mathrm{nm}))$ and SIF $(0.01 \sigma(\mathrm{MPaVm}))$ are associated with the noise level of the CCD camera $\sigma$ (expressed in gray levels, $\sigma<2$ ). More generic strategies in dealing with crack problems were developed ${ }^{21,22}$ using hybrid DIC/FE to improve measurement accuracy and using integrated DIC to measure the deformation and to identify SIFs at the same time. Vanlanduit et $a f^{23}$ monitored the displacement field during fatigue crack growth, and they found that the errors increase with the increase of displacement amplitude and the increase of speckle size. Xu et $a^{24}$ examined the measurement uncertainty of local deformation near a crack tip, and they found that the measured displacement and strain results are strongly affected by a number of parameters including subset size, step size and the size of strain calculation window. They estimated that displacement systematic errors are proportional to the second-order displacement gradients and are dependent on subset size; whilst strain systematic errors are functions of the third-order displacement gradients, which are dependent on subset size, step size and the size of strain measurement window. Mokhtarishirazabad et $a l^{25}$ examined the influence of a number of DIC processing parameters on the accuracy of SIF estimation. They concluded that SIF K, may be affected by the size of FOV, subset size, the position of the crack inside of FOV and the number of terms in the Williams' series. Unlike a recommendation of excluding plastic zone area in the estimation of $K_{1}^{21}$ they suggested that, if a sufficiently large FOV is used plastic zone area does not seem to affect the estimation of SIF using the displacement data from DIC. Including about $25 \%$ of the crack in the area of interest is recommended, whilst including more terms in the Williams' expansion does not appear to further improve the accuracy of the estimated $\mathrm{K}^{25} \mathrm{~A}$ parametric analysis ${ }^{26}$ of measurement uncertainties in displacements and strains of a cracked specimen was carried out under selected loading conditions based on Xu et al. ${ }^{24}$ Full-field errors in displacements were also estimated under loads for selected subset sizes, as shown in Fig. 3. The random errors appear to decrease with the increase of subset size; whilst the systematic errors appear to increase with the increase of subset size, hence a compromise is needed to minimise the overall errors. A subset size about 5 times the speckle/feature size was found to be a good compromise as a trade-off between systematic and random errors, with a step size of $1 / 4$ of the subset size or smaller recommended. The size of strain measurement window 
is another important parameter for strain estimation, although the measurement uncertainties are more difficult to assess with respect to systematic errors. One way of estimation may be by the method of virtual strain gauge (VSG), ${ }^{27}$ where a VSG was placed along y-direction and strains were evaluated (Fig. 3) at the most sensitive position (crack tip) at selected subset and step sizes. A subset size of 43 pixels and a step size of 12 pixels were found to produce the most "converged" results amongst the results obtained by combinations of subset sizes (23-75 pixel) and step sizes (2-19 pixel) for this application. ${ }^{26}$

\section{DETERMINATION OF FRACTURE MECHANICS PARAMETERS}

One of the first applications of DIC technique in fracture mechanics studies is the estimation of stress intensity factor (SIF), K. ${ }^{10,20-22,28-42}$ Explicit stress and displacement fields near a crack tip may be derived from the Westergaard ${ }^{43}$ functions using the general KolossovMuskhelishvili potentials. ${ }^{44} \mathrm{~A}$ characteristic feature of these solutions is that stresses have an inverse square root singularity at the crack tip and the functional forms of these near-tip stress and displacement fields do not depend on the applied load and the geometry of the cracked body. Williams ${ }^{45}$ provided crack tip asymptotic solutions using the Eigen function expansion method. An evaluation of Muskhelishvili and Williams' approaches was presented in the determination of SIFs and T-stress, ${ }^{46}$ with a recommendation in favour of Williams' method, based on studies of mixed mode I and II SIFs and T-stress. To date, Williams' series expansion (Equation 1,2) seems to be the most frequently used method for the estimation of SIFs from the displacement data of DIC.

$$
\begin{aligned}
& u(r, \theta) \\
& =\sum_{n=0}^{N} \frac{1}{2 \mu} a_{n} r^{\frac{n}{2}} \times\left\{\left(\kappa+\frac{n}{2}+(-1)^{n}\right) \cos \frac{n \theta}{2}-\frac{n}{2} \cos \left(\frac{n}{2}-2\right) \theta\right\} \\
& +\sum_{n=0}^{M} \frac{1}{2 \mu} b_{n} r^{\frac{n}{2}} \times\left\{\left(-\kappa-\frac{n}{2}+(-1)^{n}\right) \sin \frac{n \theta}{2}+\frac{n}{2} \sin \left(\frac{n}{2}-2\right) \theta\right\}
\end{aligned}
$$

$$
\begin{aligned}
& v(r, \theta) \\
& =\sum_{n=0}^{N} \frac{1}{2 \mu} a_{n} r^{\frac{n}{2}} \times\left\{\left(\kappa-\frac{n}{2}-(-1)^{n}\right) \sin \frac{n \theta}{2}+\frac{n}{2} \sin \left(\frac{n}{2}-2\right) \theta\right\} \\
& +\sum_{n=0}^{M} \frac{1}{2 \mu} b_{n} r^{\frac{n}{2}} \times\left\{\left(\kappa-\frac{n}{2}+(-1)^{n}\right) \cos \frac{n \theta}{2}+\frac{n}{2} \cos \left(\frac{n}{2}-2\right) \theta\right\}
\end{aligned}
$$

where $u$ and $v$ are displacements in $\mathrm{x}$ and $\mathrm{y}$ directions; $a_{n}$ and $b_{n}$ are related to mode $\mathrm{I}$ and mode II parts of deformation, respectively. $\mu$ is the shear modulus and $\kappa=(3-v) /(1+v)$ for plane stress, $v$ is the Poisson's ratio; $r$ is the radial distance from crack tip and $\theta$ is the phase angle in a polar coordinate system with the crack tip at the centre. Note that rigid body movements must be removed from the DIC displacement data before regression can be carried out, this function is usually available from commercial DIC software. 
One of the earliest studies to determine SIFs from displacement data was Evans and Luxmoore ${ }^{47}$ who used a laser speckle method to plot displacement perpendicular to the crack plane versus the root of the radial distance to the crack tip, and compared the correlation with the solution of Westergaard. ${ }^{43}$ Chiang and Asundi ${ }^{28}$ determined SIF from the displacement field around a crack tip using a light speckle method; whilst McNeil et al ${ }^{10}$ estimated SIF $K_{1}$ using a least square method from the displacement data of image correlation. Only data perpendicular to the crack plane were considered and the errors between the analytical and the experimental results were assessed. It is now known that fullfield data should be used, as ignoring data horizontal to the crack plane may be a main source of errors. ${ }^{46}$ Roux and Hild ${ }^{20-22}$ systematically studied the topic of extracting SIFs of a fatigue crack from DIC data based on Kolossov-Muskhelishvili potentials, proposed alternative routes such as injecting displacement field from DIC into a finite element shape function and obtain the fracture mechanics parameters; or an integrated approach by directly estimating them at the same stage as the DIC measurements. Mixed mode SIFs were obtained by using higher-order terms ${ }^{28}$ of Williams' solution, although some argued that the use of higher than 3 terms does not improve the accuracy of the fitted values of SIF. ${ }^{25,46}$ The effects of anisotropy on the SIFs were studied ${ }^{35,36}$ in single crystal materials, where an anisotropic least-squares regression algorithm was used to find the SIFs and the T-stress from the displacements obtained from DIC. Inclusion of T-stress in the regression was shown to have improved the regression accuracy (Figure 5). ${ }^{30}$

The determination of crack tip position was a subject of interest for a number of researchers, ${ }^{20-22,46,48}$ as an accurate determination of the position of crack tip is shown to be important for the estimation of SIFs. McNeil et $a l^{10}$ estimated the crack tip position by seeking a minimal from the error function defined. Roux and Hild ${ }^{20-22}$ discussed the strategies of determination of crack tip position, where the non-linear process zone closest to the crack tip was removed, and an effective crack tip position was estimated from the relative importance of amplitudes associated with the Eigen functions for mode I and mode II. In doing so they reported an uncertainty of crack tip position of about $20 \mu \mathrm{m}$ for a crack of $15 \mathrm{~mm}$. Zanganeh ${ }^{46}$ evaluated the effects of crack tip position on the estimated SIFs and T values, and found that underestimation of crack length increased $K_{1}$ but decreased T-stress. An iterative Newton-Raphson technique was proposed to solve the crack tip coordinates as unknowns in the Williams equations, using the displacement data from DIC with improved results. A simple method of estimation of crack tip position was proposed by Zhu et $\mathrm{al}^{4}{ }^{48}$ where the vertical coordinate of a crack tip was determined by averaging all the vertical displacements from DIC in the field of view.

The path-independent J integral approach has been used to estimate SIFs. ${ }^{41,42,49}$ The advantage of this approach over the previous approaches is that it does not require the precise knowledge of crack tip position. So long as the crack tip is included in the integration domain and Small Scale Yield (SSY) conditions satisfied, the values of J obtained will not be affected by the crack tip position. The method is more susceptible to scatters in the raw data though, as it requires information of stress and strain, which are obtained from the numerical differentiation of displacement data. Raw displacement data should be filtered and smoothed before differentiation operation to reduce noise levels. 
Although the success of estimation of SIF using the full-field displacement data from DIC can be readily measured by a comparison between the analytical and the fitted values, the significance of these exercises beyond gaining confidence in the application of DIC technique to crack problems is somewhat unclear. In the majority of the cases reported, the values of fitted SIF seem to be close to the nominal values. It was argued that only data from the field of view where K-dominance applies should be used in the fitting, as DIC measures total strains. However, in practice some ${ }^{25}$ found that excluding plastic region ${ }^{21}$ seems to be unnecessary. Nevertheless, the extent of plasticity should be considered in deciding the size of field of view, as high resolution DIC may have a limited field of view where the plastic component may be substantial in comparison to the elastic component, consequently overestimation of SIF may occur due to the high total strain as a result of plastic deformation (Fig. 6) ${ }^{50}$. Sometimes, simple estimation ${ }^{31}$ of SIF from discrete displacement data on the crack flank (Equation 3 ) is deemed suffice:

$$
u_{i}= \pm \frac{4 K_{I}}{E} \sqrt{\frac{r_{i}}{2 \pi}}
$$

where $K_{l}$ is the elastic stress intensity factor, $E$ is Young's Modulus, $u_{i}$ and $r_{i}$ are the vertical displacement and the distance from the crack tip at point i. Further work is required to assess the results from such a simple estimation and the fitted values from the full-field displacement data.

In addition to SIFs and T-stress, DIC data have also been used for the identification of other fracture mechanics parameters, such as plastic flow under mixed mode loading, ${ }^{51}$ crack propagation law, ${ }^{34,52}$ monitor crack growth, ${ }^{23}$ parameters in cohesive law, ${ }^{53}$ estimating plastic zone size ${ }^{37}$ and crack opening displacement, ${ }^{8,30,31}$ the latter will be discussed in the following chapter. DIC measures total displacements/strains, hence plastic components normally need to be separated from the total using numerical methods together with suitable materials constitutive models (Fig $7^{37}$ ). Decreuse et a ${ }^{51}$ partitioned deformation under mixed mode loading conditions into elastic and plastic parts by considering unloading to be essentially elastic. They utilised a generalised von Mises criterion to determine a threshold for plastic flow, also estimated the plastic flow direction. Hos et al ${ }^{54}$ utilised DIC in the measurements of strain fields around crack tips under proportional and non-proportional mixed mode fatigue loading (Fig. 8). They used selected data local to the crack tips to estimate SIFs and COD from a least square analysis of the first term of Westergaard solution. Mathieu et al ${ }^{52}$ used an integrated DIC procedure to identify several fracture mechanics parameters, including determination of crack tip position, SIF, T-stress, plastic zone estimation and fitting of constants of Paris law; whilst Roux-Langlois et al $^{34}$ further developed their approach using full-field measurement and enriched numerical simulations where boundary conditions were prescribed from the displacement fields measured by DIC. It seems that a hybrid approach of DIC and X-FEM offers most promising improved solutions to crack problems.

Full-field measurements using DIC allow the determination of fracture mechanics parameters from interested specimen geometries and loading conditions, hence offer significant progress on the studies of crack driving force and other mechanical parameters for structural integrity assessments of engineering structures and components. It is reassuring that, for most cases reported, the fitted values of the parameters from the DIC measurements appear to be close 
to the analytical solutions when SSY condition is satisfied, although, admittedly, the measurements are limited to surfaces. Parameters in 3D will need to be estimated from further analysis, for example, using hybrid approaches such as DIC and X-FEM.

\section{EVALUATION OF CRACK CLOSURE}

The use of DIC to evaluate microscale displacements and strains near a fatigue crack tip was first reported by Sutton et al. ${ }^{8}$ Crack opening was measured at two locations (75 $\mu \mathrm{m}$ and 224 $\mu \mathrm{m})$ behind the crack tip for AA8009 steel alloy at $\Delta \mathrm{K}=4.4 \mathrm{MPa} \sqrt{\mathrm{m}}(\mathrm{R}=0.05)$. Higher value of $\mathrm{P}_{\mathrm{op}} / \mathrm{P}_{\max }(\approx 0.26)$ was obtained at $75 \mu \mathrm{m}$ than that at $224 \mu \mathrm{m}$ to the crack tip $\left(\mathrm{P}_{\mathrm{op}} / \mathrm{P}_{\max } \approx 0.15\right)$. Carroll et al $^{29}$ used the DIC method to examine crack opening in both macro and micro scales at three stress intensity factor ranges $(9.7,15.4$ and $18.9 \mathrm{MPa} \sqrt{\mathrm{m}})$ in a Grade 2 Titanium. Their results show that crack opening $\mathrm{P}_{\mathrm{op}} / \mathrm{P}_{\max }$ varies with the location of the measurement gauge, load level and the measurement resolution. Crack opening load increases with the reduction of the distance to the crack tip; decreases with the reduction of the measurement magnification, with $P_{\text {op }}$ found between $5-15 \%$ at $3.9 \mu \mathrm{m} /$ pixel and $15-30 \%$ at $0.33 \mu \mathrm{m} /$ pixel of $P_{\max }$. There appeared to be little crack closure at $\Delta \mathrm{K}=18.9 \mathrm{MPa} \sqrt{\mathrm{m}}$, although they used three different specimens and argued that the short crack with regard to the notch length in this specimen was attributed to the latter observation.

Lopez-Crespo et $\mathrm{al}^{54}$ identified crack closure under mixed mode I and II loading conditions by fitting SIFs using the displacements obtained from DIC, and the effects were attributed to combined effects of plasticity, roughness and frictional forces. O'Connor et al ${ }^{31}$ conducted both macro and micro DIC analysis of the near-tip displacements and strains using a 6082-T6 aluminum alloy. They also showed that the opening load is higher for locations closer to the crack tip, as the crack peels open from the crack mouth towards the crack tip. For constant amplitude fatigue, the fitted $\mathrm{K}$ using displacement data from DIC broadly followed the analytical K, although with an offset, which they attributed to crack closure due to an additional negative residual $K$. Casperson et al ${ }^{55}$ studied crack closure at elevated temperature under isothermal, thermal jump and thermal overload conditions. They showed a closure level about 0.3 for isothermal conditions whilst there was little crack closure following a temperature change, somewhat similar to that reported following mechanical overloads. ${ }^{31,40}$ Rabbolini et al $^{57}$ measured crack opening levels by placing a virtual strain gauge behind the crack tip, and found that they differed from those measured remotely using extensometer or those estimated by Newman's model. ${ }^{58}$ Recently, full-field characterisation has been used to revisit the crack closure phenomenon, ${ }^{59}$ both events behind and ahead of the crack tip were examined as well as the estimation of $\mathrm{K}$ as a function of load. Crack opening $\left(\mathrm{P}_{\mathrm{op}} / \mathrm{P}_{\max }\right)$ was found to decrease with the decrease in measurement resolution, the increase in the distance to the crack and the increase in load level; and the values of $\mathrm{P}_{\mathrm{op}} / \mathrm{P}_{\max }$ in the COD vs load curves do not appear to correlate with the changes in the fitted $\mathrm{K}$ from the displacement data. Furthermore, the near-tip normal strains are found to increase continuously with the increase of the applied load, and do not correlate with the trend presented in the COD vs load curves. The lack of uniqueness in "crack opening" is consistent with the results of Carroll et ll $^{30}$ and others. ${ }^{19,31}$

The effects of mechanical overloads on crack closure have been reported in a number of studies. Yusof et $\mathrm{al}^{40}$ showed no crack closure immediately after an overload, although a "knee" in both COD and fitted $\Delta \mathrm{K}$ was observed pre and post the overload, results supported 
by O'Connor et $a^{31}$ from a micro-mechanics study using DIC on small samples tested within a SEM. The lack of crack closure following an overload was also confirmed by a study ${ }^{40}$ using a J-integral approach, where a knee in the fitted K vs load was found pre-overload, but not post overload, from the measured displacements by DIC. Closure effects were also assessed at elevated temperature ${ }^{60}$ but the trend was found to be similar to that at room temperature.

It seems that consistent results have been obtained in the measurement of crack closure, which may be summarised as: i) Cracks tend to open from behind and gradually reach the crack tip from the crack mouth during loading; ii) there appears to be a "knee", identified as "crack opening" in the measured COD vs load curve, under constant amplitude fatigue, although the precise moment at which a crack "opens" varies with the measurement position to the crack tip, the applied load level and the spatial resolution (Fig. 9). More significantly, the values of the fitted $K$ (Equations 1-3) from the displacement data do not appear to correlate with the applied load in the same way as the "knee" identified from the COD vs load curves, ${ }^{59}$ indicating the lack of direct impact of crack closure on the actual crack driving force. These findings re-open the long-standing debate on the concept of fatigue crack closure and its role, if any, on the attenuation of crack driving force, an area for further studies.

\section{MICRO-MECHANICS APPROACH TO FATIGUE CRACK GROWTH}

Full-field characterization using high resolution DIC technique opens an exciting new perspective to micro-mechanics studies of fatigue cracks. Carroll et al ${ }^{61,62}$ investigated the interactions between strain accumulation, microstructure, and fatigue crack behaviour; and mapped plastic strain accumulation due to fatigue crack growth at sub-grain level. The accumulated plastic strain fields associated with fatigue crack growth were found to be highly inhomogeneous, varied from grain to grain and within individual grains; and strain localization was evident in slip bands within grains and on twin and grain boundaries (Fig. 10). At the macroscale, the plastic wake contained asymmetric high strain lobes associated with the plastic zones left by deformation due to previous loading. Peralta et al ${ }^{63}$ found strain localization along deformation bands which are asymmetrical and crystallographic; and the crack advance was found to be approximately proportional to an integrated strain, an area integral of an "opening" strain with a power law relationship with $\Delta \mathrm{K}$. The integrated strain was related to the accumulated displacement in the deformation bands. This, in turn, was proportional to the product of the cyclic plastic zone radius and the average shear strain ahead of the tip. The crack growth was found to be approximately proportional to the integrated strain.

Near-tip strain accumulation has been monitored in situ during cyclic loading, ${ }^{50,64-66}$ and quantitative experimental evidence of normal strain ratchetting has been found ahead of the crack tip, in support of a hypothesis of strain ratchetting as a mechanism for fatigue crack growth. ${ }^{67,68}$ In addition, strains have been monitored at selected, fixed observation points ${ }^{64-66}$ in the field of a growing fatigue crack, and a critical or onset strain was identified from instantaneous strains at the crack tip as the crack approached the observation points (Fig. 11). Such information is significant towards discovering a local crack driving force, albeit within a continuum mechanics domain. On the other hand, microstructural information, together with high resolution DIC measurement, may be used to identify individual slip 
system activities and relate such to fatigue crack initiation and growth. ${ }^{61}$ The quantitative information will also inform and validate modelling efforts so that reliable multiscale analysis could be carried out. More recently, Malitckii et al ${ }^{69}$ examined strain accumulation by DIC during microstructurally small fatigue crack propagation in a polycrystalline stainless steel. They found intermittent appearance of the shear strain localization zones ahead of the crack tip as the fatigue crack propagates (Fig. 12). The fatigue crack growth rate seems to correlate with the accumulated shear deformation; and the relationship between the grain orientation and the shear strain intensity is inversely proportional. The crack growth occurs predominantly by a single shear mechanism in the direction of the primary slip system, when a critical shear strain ahead of the crack tip is reached (Fig. 13). The prospect of in situ experiments such as this is immensely exciting, as they open windows into local deformation under cyclic loading towards the discovery of crack driving force at a microscopic level, which may also impact on future materials design as well as characterization.

\section{CONCLUDING REMARKS}

Full-field characterisation of fatigue cracks and fatigue crack growth using DIC has allowed in situ studies of near-tip deformation, ahead and behind of the crack tip, for the first time. This is of considerable significance in that fatigue crack driving force may be assessed the same time as crack attenuation events under given loading conditions and for specimens/materials of interest. As displacements and strains may be mapped in situ during crack growth at high resolutions, it is possible to explore local crack driving force and investigate the relationships between global and local crack driving forces, so that engineering solutions may be developed from a fundamental understanding of physical mechanisms of crack growth.

Although significant progress has been made in the quantitative analysis of deformation due to fatigue cracks using DIC, further studies are required to clarify a number of issues. First of all, although most reported values of $\mathrm{K} / \mathrm{J}$ fitted from the displacement data of DIC compare favorably with the corresponding analytical values, there seems no consensus $s^{30-32,34,41,46,59}$ on the relationship between the fitted values of $K$ and the load during loading/unloading. Although the measured COD vs load curves confirmed the presence of crack closure in most cases, the $\mathrm{K}$ fitted from the displacement data does not appear to follow the same trend, neither does the near-tip strain evolution ahead of the crack tip. These discrepancies cast some doubts on the role of crack closure in fatigue crack growth. Admittedly, significant measurement errors may affect the regression results, due to the quality of the surface features or the choice of processing parameters. For example, the number of the William's terms necessary to produce accurate SIFs was shown to be dependent on the dimension of the regression area; ${ }^{70}$ overestimation of $\mathrm{K}$ may occur if a field of view contains significant plastic deformation; on the other hand, underestimation may also occur for in situ measurements if data capture is too fast. At least 10s should be allowed for data capture, if underestimation is to be avoided. Further work is needed to examine the issue broadly in more materials/specimens so generic, conclusive evidence may be established. Although high resolution DIC affords mapping of strains at sub-grain levels, quantitative measures are yet to be obtained towards a physical-based crack growth model through a fundamental understanding of micro-mechanics behaviour of materials. 
Admittedly, only surface deformation can be measured using DIC. Although, incidentally, this is ideal for the assessments of classic cases such as plasticity-induced crack closure or crack growth under plane stress conditions. 3D bulk material responses in the presence of cracks are essential for damage tolerant assessments of engineering structures and components. This will require more sophisticated tools such as synchrotron/neutron diffraction and X-ray tomography. ${ }^{71}$ Deformation behaviour near a fatigue crack tip was studied by spatially resolved, in situ, measurements of lattice strains using neutron diffraction technique, ${ }^{72}$ for example. The recent advances in lab-based 3D X-ray tomography, together with digital volume correlation (DVC), offer an exciting new perspective to the characterisation of 3D fatigue crack growth, provided that "features" in the microstructure can be sufficiently resolved in the volume of interest.

\section{REFERENCES}

1. Paris PC, Gomez MP, Anderson WE. A rational analytic theory of fatigue. Trend Eng. 1961; 13:9-14.

2. Rice JR. Mechanics of Crack Tip Deformation and Extension by Fatigue. Fatigue Crack Propagation. 1967; ASTM STP 4:247-309.

3. Schijve J. Fatigue of structures and materials in the 20th century and the state of the art. Int J Fatigue. 2003;25:679-702.

4. Elber W. Fatigue Crack Closure Under Cyclic Tension. Eng Fract Mech. 1970;2:37-45.

5. Suresh S. Fatigue of Materials: 2nd ed. Cambridge: Cambridge University Press; 1998.

6. Pippan R, Hohenwarter A. Fatigue crack closure: a review of the physical phenomena. Fatigue Fract Eng Mater Struct. 2017;40:471-95.

7. Vasudeven AK, Sadananda K, Louat N. A review of crack closure, fatigue crack threshold and related phenomena. Mater Sci Eng A. 1994;188:1-22.

8. Sutton MA, Wolters W, Peters WH, Ranson W, McNeill S. Determination of displacements using an improved digital correlation method, Image Vis. Comput. 1983; 1:133-139. doi:10.1016/0262-8856(83)90064-1.

9. Sutton MA, Orteu JJ, Schreier H. Image correlation for shape, motion and deformation measurements: Basic concepts, theory and applications, 1st ed., Springer US, Boston, MA, 2009. doi:10.1007/978-0-387-78747-3.

10. McNeill S, Peters WH, Sutton MA. Estimation of stress intensity factor by digital image correlation, Eng Fract Mech. 1987;28(1):101-112.

11. Ritchie RO. Mechanisms of fatigue crack propagation in metals, ceramics and composites: Role of crack tip shielding. Mater Sci Eng. 1988;103:15-28.

12. Bornert M, Bremand F, Doumalin P, Dupre JC, Fazzini M, Grediac M, Hild F, Mistou S, Molimard J, Orteu JJ, Robert L, Surrel Y, Vacher P, Wattrisse B, Assessment of digital image correlation measurement errors: Methodology and results. Exp. Mech. 2009;49:353-370. 13. Pan B, Xie H, Wang Z, Qian K, Wang Z. Study on subset size selection in digital image correlation for speckle patterns. Opt. Express. 2008;16:7037-7048.

14. Crammond G, Boyd SW, Dulieu-Barton JM. Speckle pattern quality assessment for digital image correlation. Opt. Lasers Eng. 2013;51:1368-1378.

15. Fazzini M, Mistou S, Dalverny O, Robert L. Study of image characteristics on digital image correlation error assessment. Opt. Lasers Eng. 2010;48:335-339. 
16. Lecompte D, Smits A, Bossuyt S, Sol H, Vantomme J, Van Hemelrijck D, Habraken AM. Quality assessment of speckle patterns for digital image correlation. Opt. Lasers Eng. 2006;44:1132-1145.

17. Schreier H, Sutton MA. Systematic Errors in Digital Image Correlation Due to Undermatched Subset Shape Functions. Exp. Mech. 2002;42:303-310.

18. Knauss WG, Chasiotis I, Huang Y. Mechanical measurements at the micron and nanometer scales. Mech. Mater. 2003;35: 217-231.

19. Sutton MA, Mingqi C, Peters W, Chao Y, McNeill S. Application of an optimized digital correlation method to planar deformation analysis. Image Vis. Comput. 1986;4:143-150.

20. Roux S, Hild F. Stress intensity factor measurements from digital image correlation: postprocessing and integrated approaches. Int J Fracture 2006; 140:141-157

21. Hamam R, Hild F, Roux S. Stress intensity factor gauging by digital image correlation: application in cyclic fatigue. Strain 2007;43:181-92.

22. Roux S, Réthoré J, Hild F. Digital image correlation and fracture: an advanced technique for estimating stress intensity factors of 2D and 3D cracks. J. Phys. D. Appl. Phys. 2009;42:214004.

23. Vanlanduit S, Vanherzeele J, Longo R, Guillaume P. A digital image correlation method for fatigue test experiments. Opt. Lasers Eng. 2009;47:371-378.

24. Xu X, Su Y, Zhang Q. Theoretical estimation of systematic errors in local deformation measurements using digital image correlation. Opt. Lasers Eng. 2017;88:265-279.

25. Mokhtarishirazabad M, Lopez-Crespo P, Moreno B, Lopez-Moreno A, Zanganeh M. Evaluation of crack-tip fields from DIC data: A parametric study. Int J Fatigue. 2016;89:11-9. 26. Wigger T, Lupton C, Tong J. A parametric study of DIC measurement uncertainties of cracked metals. Strain, under view.

27. P. Reu, Virtual Strain Gage Size Study, Experimental Techniques 2015; 39:1-3.

28. Chiang FP, Asundi A. A white light speckle method applied to the determination of stress intensity factors and displacement field around a crack tip. Eng. Fract. Mech. 1981;15:115121.

29. Yoneyama S, Ogawa T, Kobayashi Y. Evaluating mixed-mode stress intensity factors from full-field displacement fields obtained by optical methods. Eng Fract Mech 2007;74:1399412.

30. Carroll J, Efstathiou C, Lambros J, Sehitoglu H, Hauber B, Spottswood S, et al. Investigation of fatigue crack closure using multiscale image correlation experiments. Eng Fract Mech. 2009;76:2384-98.

31. O'Connor SJ, Nowell D, Dragnevski KI. Measurement of fatigue crack deformation on the macro- and micro-scale: Uniform and non-uniform loading. Int J Fatigue. 2016;89:66-76. 32. Yates JR, Zanganeh M, Tai YH. Quantifying crack tip displacement fields with DIC. Eng Fract Mech. 2010;77:2063-76.

33. Zhang R, He L-F. Measurement of mixed-mode stress intensity factor using digital image correlation method. Optics Laser Eng. 2012;50:1001-1007.

34. Roux-Langlois C, Gravouil A, Maietto M-C, Réthoré J, Mathieu F, Hild F, Roux S. DIC identification and X-FEM simulation of fatigue crack growth based on the Williams' series. Int J Solid Struct. 2015; 53:38-47.

35. Pataky GJ, Sangid MD, Sehitoglu H, Hamilton RF, Maier HJ, Sofronis P. Full field measurements of anisotropic stress intensity factor ranges in fatigue. Eng Fract Mech. 2012;94:13-28. 
36. Rabbolini S, Pataky GJ, Sehitoglu H, Berett S. Fatigue crack growth in Haynes 230 single crystals: An analysis with digital image correlation, Fatigue and Fracture of Engineering Materials and Structures. 2015; 38:583-596.

37. Besel M, Breitbarth E. Advanced analysis of crack tip plastic zone under cyclic loading. Int J Fatigue. 2016;93:92-108.

38. Andrieux S, Baranger TN. Three-dimensional recovery of stress intensity factors and energy release rates from surface full-field displacements. Int J Solid Struct. 2013; 50:15231537.

39. Abshirim M, Soltani N, Marsshizadeh P. On the mode I fracture analysis of cracked Brazilian disc using a digital image correlation method. Optics Laser Eng. 2016;78:99-105. 40. Yusof F, Lopez-Crespo P, Withers PJ. Effect of overload on crack closure in thick and thin specimens via digital image correlation. Int J Fatigue. 2013;56:17-24.

41. Gonzales GLG, Gonzalez JAO, Castro JTP, Freire JLF. A J-integral approach using digital image correlation for valuating stress intensity factors in fatigue cracks with closure effects. Theo. Appl Fract Mech. 2017, in press.

42. Becker TH, Mostafavi M, Tait RB, Marrow TJ. An approach to calculate the J-integral by digital image correlation displacement field measurement. Fatigue Fract Eng Mater Struct. 2012; 35:971-984.

43. Westergaard HM, Bearing pressures and cracks. J. Appl. Mech. 1939;6:49-53.

44. Muskhelishvili N I. Some Basic Problems of the Mathematical Theory of Elasticity. P. Noordholl Ltd, Groningen, Holland, 1953.

45. Williams ML. On the Stress Distribution at the Base of a Stationary Crack. J App/ Mech. 1957;24:109-114.

46. Zanganeh M. Experimental investigation of crack paths. PhD thesis, University of Sheffield, 2008.

47. Evans WT, Luxmoore A. Measurement of in-plane displacement around crack tips by laser speckle method. Eng Fract Mech. 1974;6:735-743.

48. Zhu ML, Lu YW, Lupton C, Tong J. In situ near-tip normal strain evolution of a growing fatigue crack. Fatigue Fract Eng Mater Struct. 2016;39:950-955.

49. Huntley JM, Field JE. Measurement of crack tip displacement field using laser speckle photography. Eng Fract Mech. 1988;30:779-790.

50. Lu Y-W, Lupton C, Zhu M-L, Tong J. In Situ Experimental Study of Near-Tip Strain Evolution of Fatigue Cracks. Exp Mech. 2015;55:1175-85.

51. Decreuse PY, Pommier S, Poncelet M, Raka B. A novel approach to model mixed mode plasticity at crack tip and crack growth. Experimental validation using velocity fields from digital image correlation. Int J Fatigue 2012;42:271-283.

52. Mathieu F, Hild F, Roux S. Identification of a crack propagation law by digital image correlation. Int J Fatigue 2012;36:146-154.

53. Réthoré J, Estevez R. Identification of a cohesive zone model from digital images at micron-scale. J Mech Phy Solids 2013;61:1407-1420.

54. Hos Y, Freire JLF, Vormwald M. Measurements of strain fields around crack tip under proportional and non-proportional mixed-mode fatigue loading. Int J Fatigue 2016;89:8798.

55. Lopez-Crespo P, Shterenlikht A, Yates JR, Patterson EA, Withers PJ. Some experimental observations on crack closure and crack-tip plasticity. Fatigue Fract Eng Mater Struct 2009;32:418-29. 
56. Casperson MC, Carroll JD, Lambros J, Sehitoglu H, Dodds Jr RH. Investigation of thermal effects on fatigue crack closure using multiscale digital image correlation experiments. Int J Fatigue 2014;61:10-20.

57. Rabbolini S, Beretta S, Foletti S, Cristea ME. Crack closure effects during low cycle fatigue propagation in line pipe steel: An analysis with digital image correlation. Eng Fract Mech. 2015;148:441-456.

58. Newman J. A crack-closure model for predicting fatigue crack growth under aircraft spectrum loading. In Chang J, Hudson C editors. Methods and models for predicting fatigue crack growth under random loading. ASTM, 1981. 53-84.

59. Tong J, Alshammrei S, Wigger T, Lupton C, Yates JR. Full-field characterization of a fatigue crack: Crack closure revisited. Fatigue Fract Eng Mater Struct. 2018;1-10.

60. Pataky G, Sehitoglu H, Maier HJ. Very high temperature fatigue crack growth in Haynes 230. Materials Characterization, 2012

61. Carroll JD, Abuzaid WZ, Lambros J, Sehitoglu H. On the interactions between strain accumulation, microstructure, and fatigue crack behavior. Int J Fract 2013;180(2):223-241. 62. Carroll JD, Abuzaid W, Lambros J, Sehitoglu H. High resolution digital image correlation measurements of strain accumulation in fatigue crack growth. Int J Fatigue 2013;57:140150.

63. Peralta P, Choi SH, Gee J. Experimental quantification of the plastic blunting process for stage II fatigue crack growth in one-phase metallic materials. Int J

Plast 2007;23:1763-95.

64. Tong J, Lin B, Lu YW, Madi K, Tai YH, Yates JR, et al. Near-tip strain evolution under cyclic loading: In situ experimental observation and numerical modelling. Int J Fatigue. 2015;71:4552.

65. Zhu M-L, Lu Y-W, Lupton C, Tong J. In situ near-tip normal strain evolution of a growing fatigue crack. Fatigue Fract Engng Mater Struct. 2016;39: 950-955.

66. Wigger T, Lupton C, Alshammrei S, Tong J. In situ mapping of normal strains in the field of a growing fatigue crack in a steel weld using Digital Image Correlation and Energy Dispersive Synchrotron X-ray Diffraction. Int J Fatigue, under review.

67. Zhao LG, Tong J, Byrne J. The evolution of the stress - strain fields near a fatigue crack tip and plasticity-induced crack closure revisited. Fatigue Fract Engng Mater Struct. 2004;27:1929.

68. Zhao LG, Tong J. A viscoplastic study of crack-tip deformation and crack growth in a nickel-based superalloy at elevated temperature. J Mech. Physics Solids. 2008; 56:33633378.

69. Malitckii E, Remes H, Lehto P, Yagodzinskyy Y, Bossuyt S, Hänninen H. Strain accumulation during microstructurally small fatigue crack propagation in bcc Fe-Cr ferritic stainless steel. Acta Mat. 2018;144:51-59.

70. Beretta S, Patriarca L, Rabbolini S. Stress Intensity Factor calculation from displacement fields. Frattura ed Integrità Strutturale 2017; 11.41: 269-276.

71. Wither PJ. Fracture mechanics by three-dimensional crack-tip synchrotron X-ray microscopy. Phil. Trans. R. Soc. A 2015; 373: 20130157.

72. Zheng LL, Gao YF, Lee SY, Barabash RI, Lee JH, Liaw PK. Intergranular strain evolution near fatigue crack tips in polycrystalline metals. J. Mech. Phys. Solids. 2011; 59:2307-2322. 


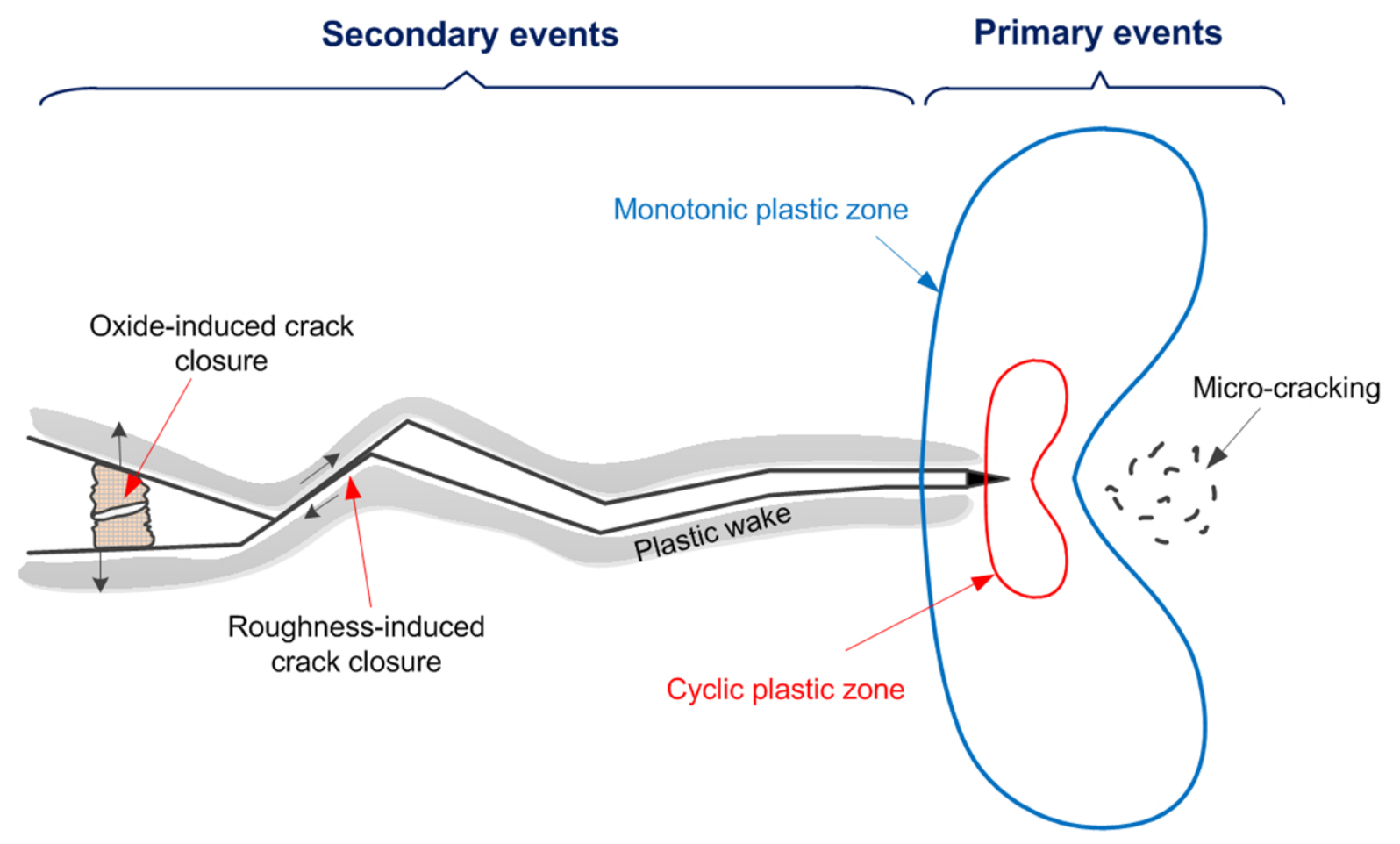

Figure 1. A schematic of some of the primary events ahead of the crack tip and secondary events behind the crack tip under cyclic loading.

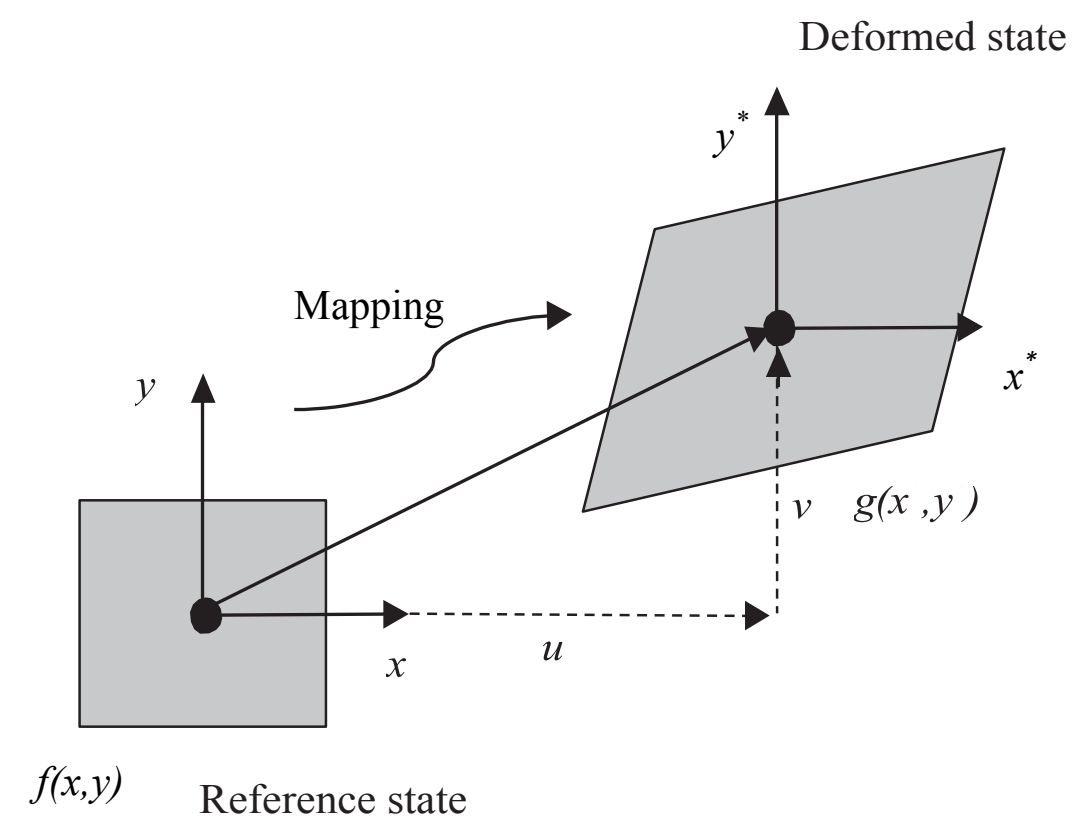

Figure 2. A schematic of the principle of Digital Image Correlation. 
Random

a) Subset 23 pixel

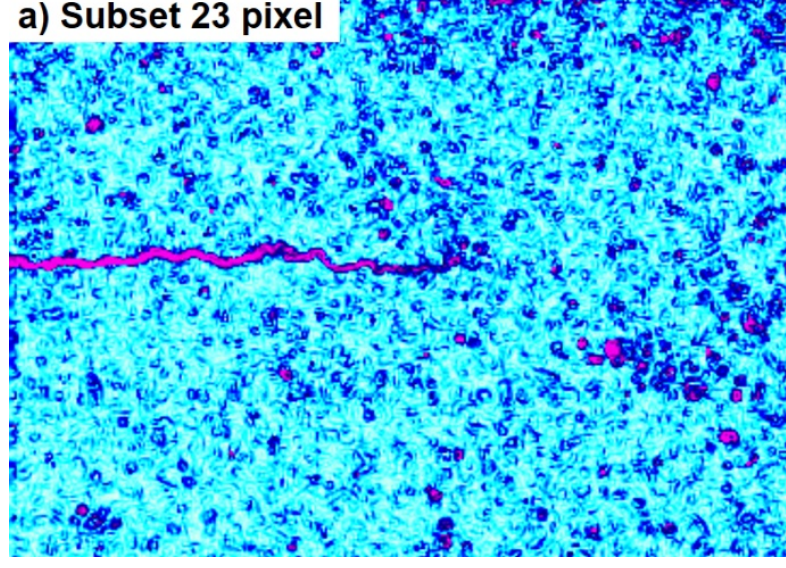

b) Subset 49 pixel

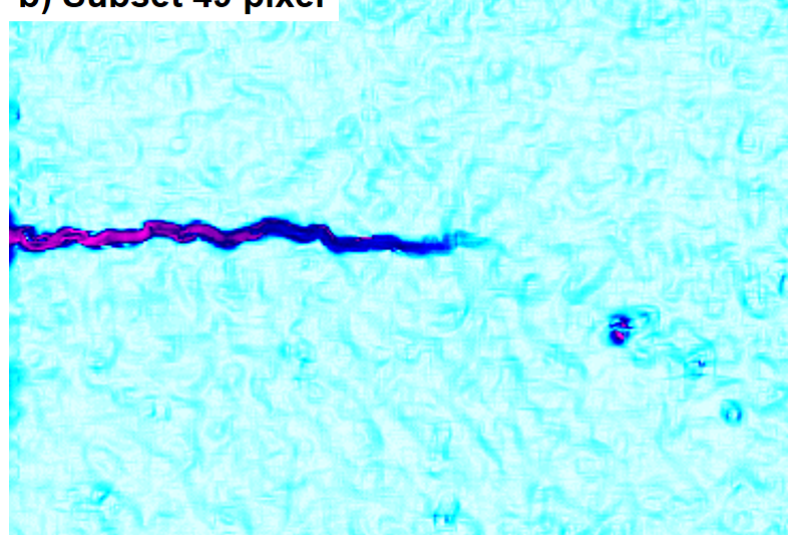

c) Subset 147 pixel

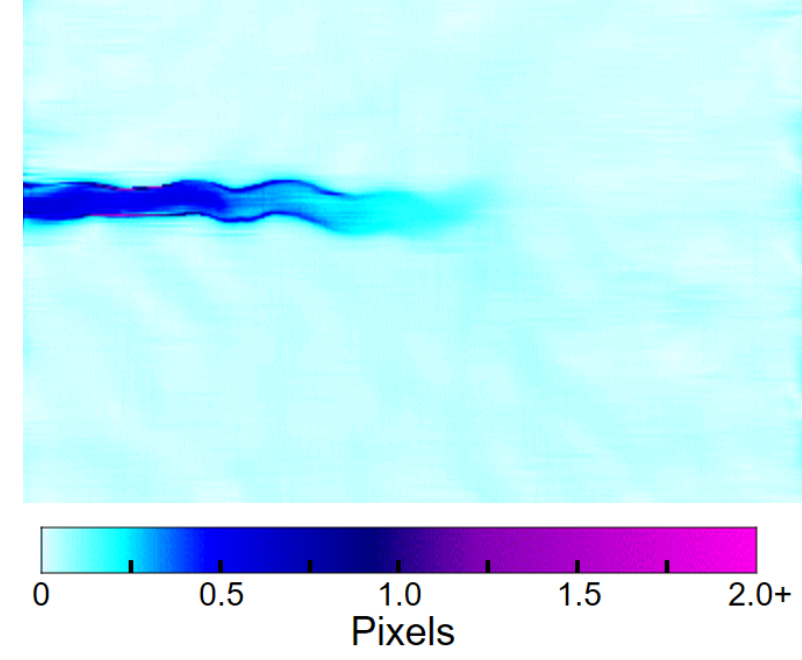

Systematic

d) Subset 23 pixel
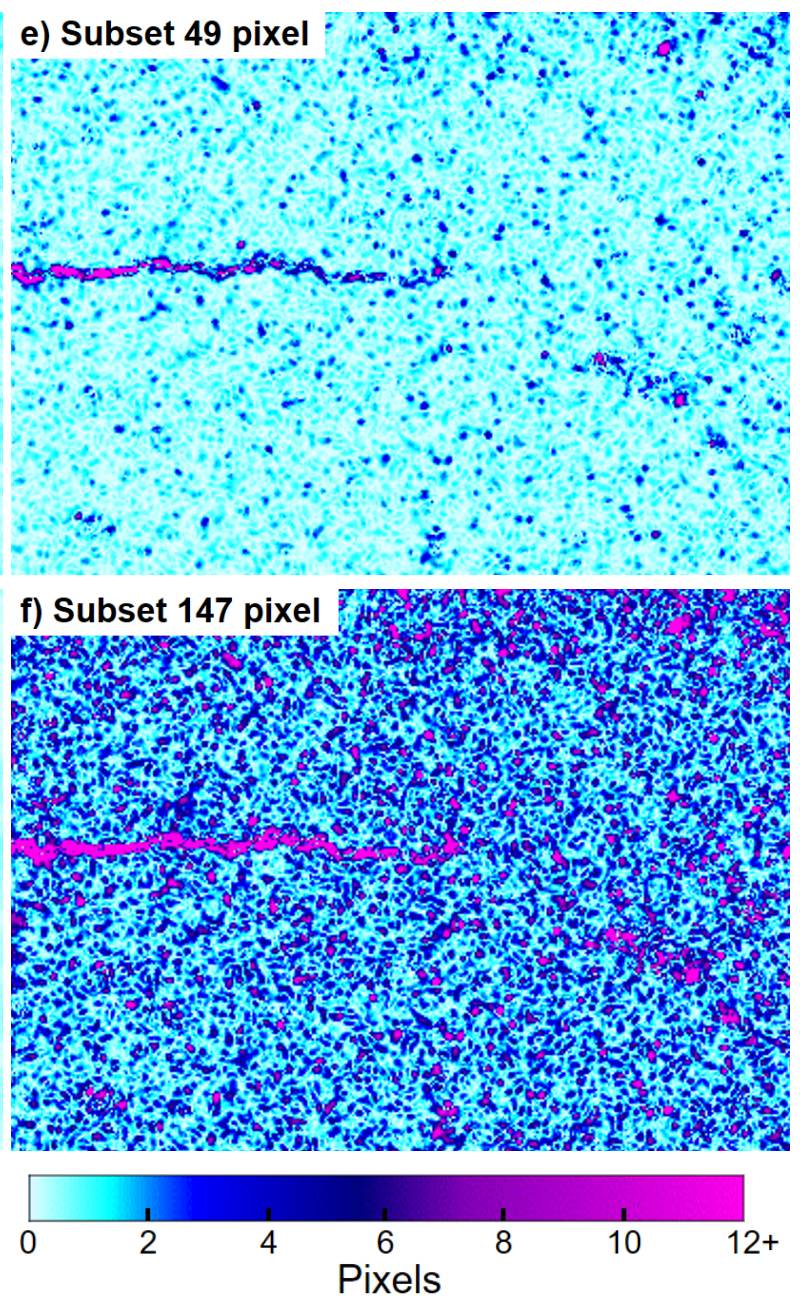

Fig. 3. The full-field displacement errors of the area correlated under $\mathrm{K}=20 \mathrm{MPa} \vee \mathrm{m}$ : Random errors (left column) and systematic errors (right column) for the selected subset sizes. ${ }^{26}$ 


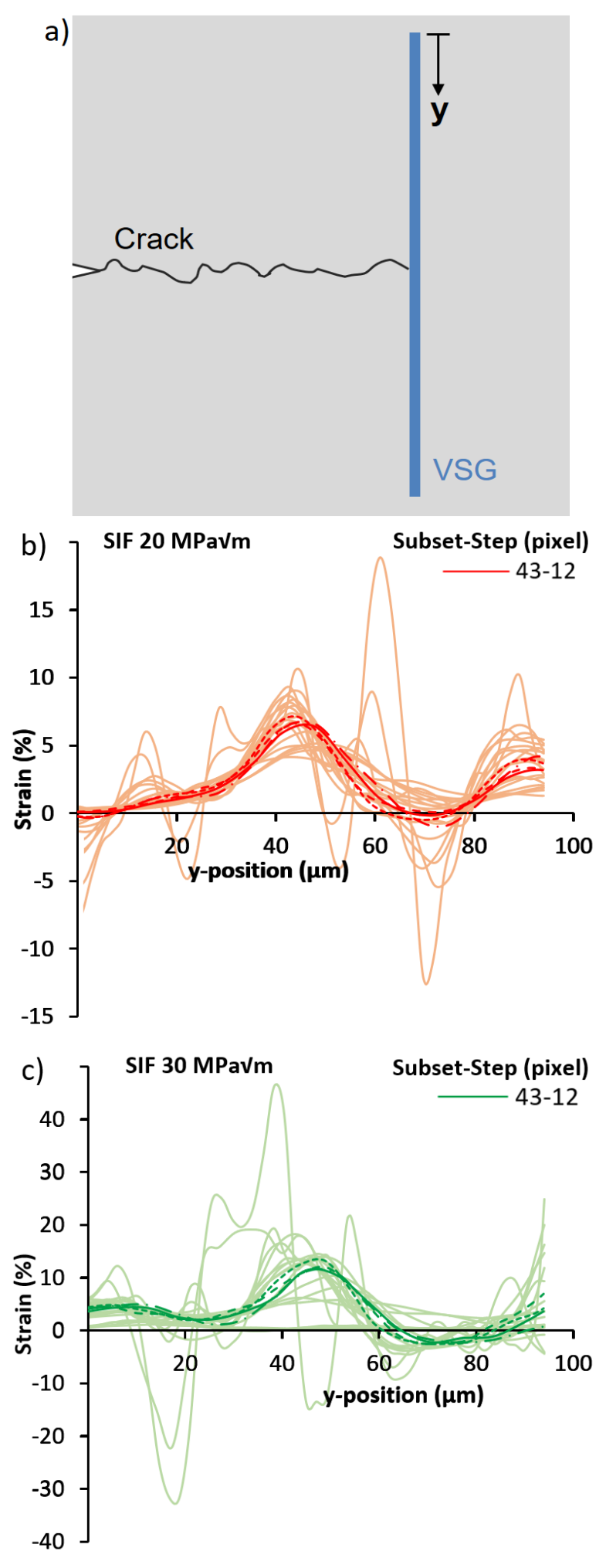

Fig. 4. a) An illustration of a Virtual Strain Gauge (VSG $)^{27}$ placed vertically at the crack tip. The normal strains were obtained under a stress intensity factor of (b) $20 \mathrm{MPa} \sqrt{\mathrm{m}}$ and (c) $30 \mathrm{MPa} \sqrt{\mathrm{m}}$. Lightweighted lines show the results from combinations of subset sizes $(23,35,43,49,61,75$ pixels) and step sizes $(4,6,9,12,19$ pixels), with the most "converged" sets (subset size-step size $=35-12$; 43-9; 43-12 and 49-9) highlighted. ${ }^{26}$ 

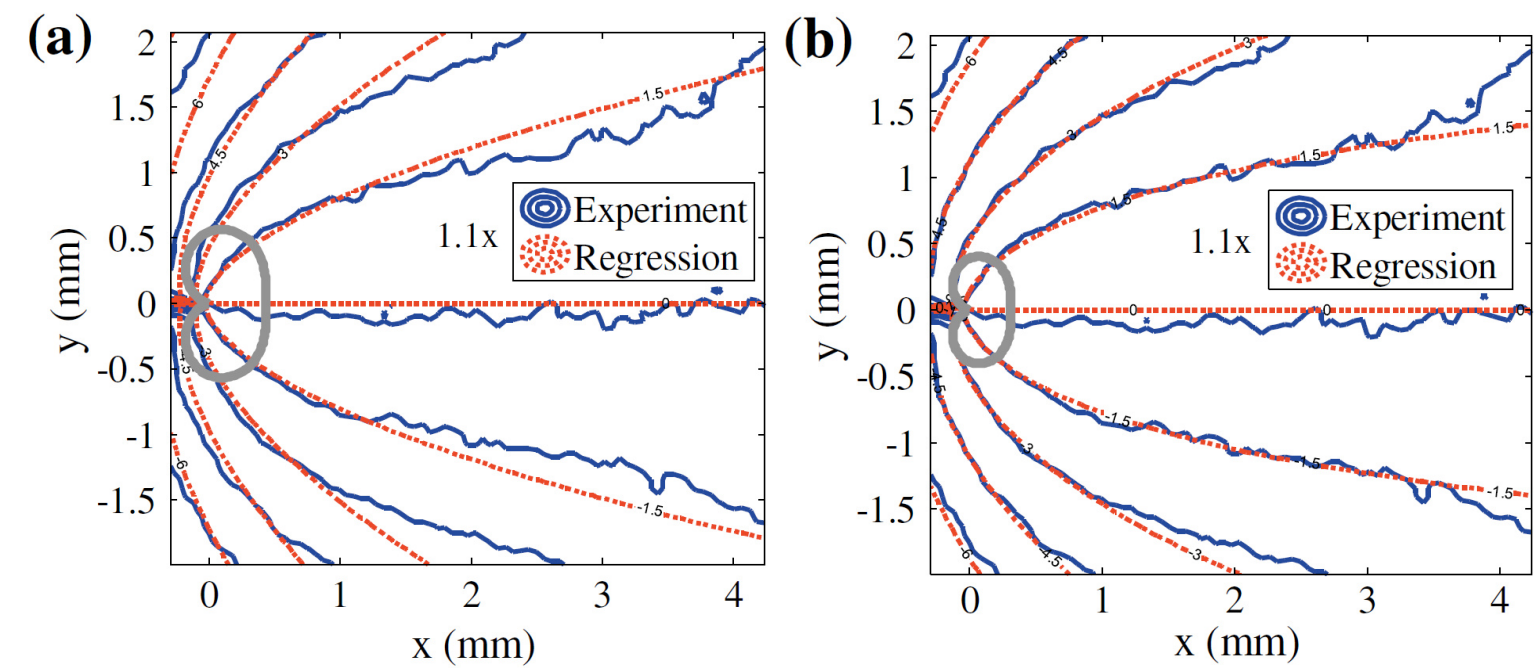

Fig. 5. Comparison of normal displacement contours measured from the experiment and the regression: (a) K-only regression and (b) K-T regression. The solid gray contour represents the approximate Von-Mises plastic zone size. ${ }^{30}$

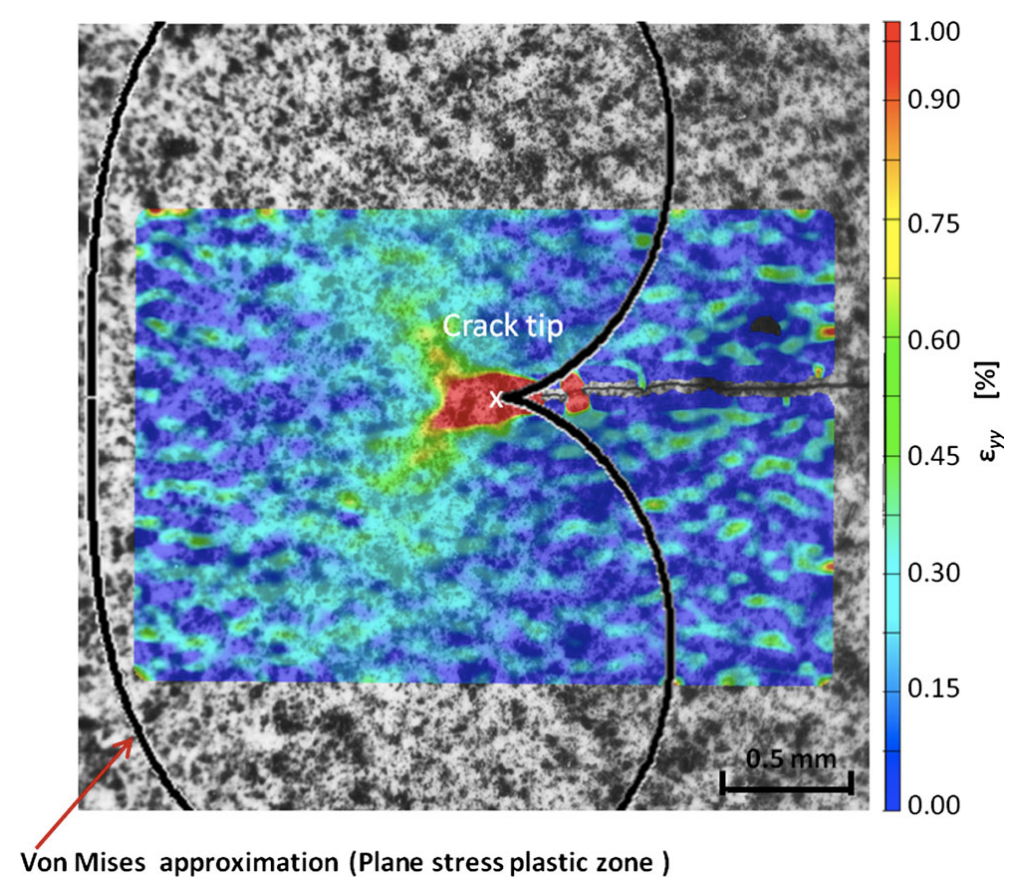

Fig 6. A typical map of normal strain $\varepsilon_{y y}$ in the field of view (FOV) including a crack tip at peak load $\left(\mathrm{K}_{\max }=28 \mathrm{MPa} \sqrt{\mathrm{m}}\right)$, superimposed over a random speckle pattern. An approximation of the planestress plastic zone from the von Mises yield criterion is also included. ${ }^{50}$ Overestimation of $\mathrm{K}$ from the DIC displacement data may occur due to the large plastic component in the FOV. 


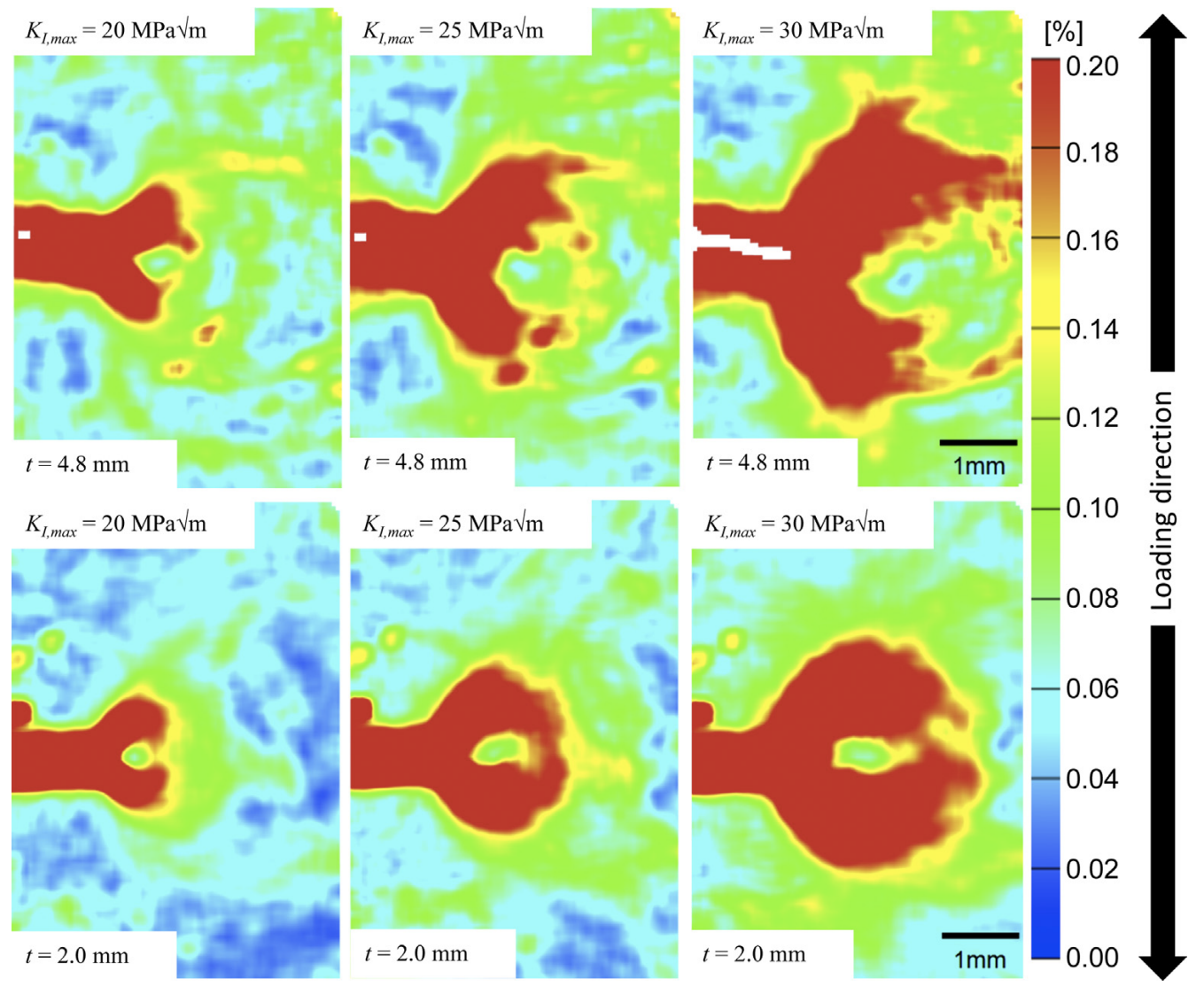

Fig. 7. The residual plastic zones expressed in equivalent strain (von Mises) in unloaded specimens of thickness $\mathrm{t}=2 \mathrm{~mm}$ and $\mathrm{t}=4.8 \mathrm{~mm} .^{37}$ 


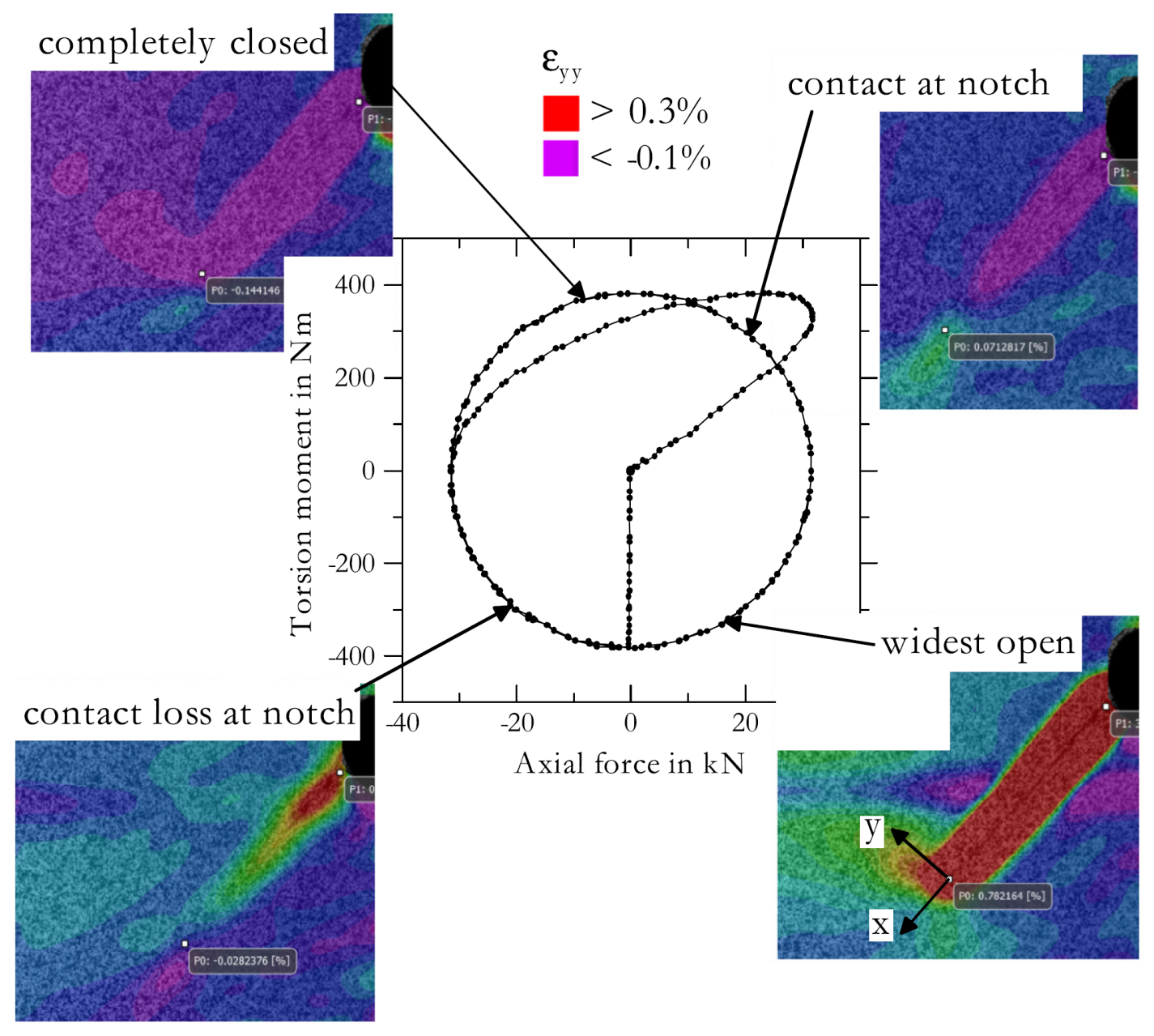

Fig. 8. The strain fields eyy under mixed mode tension-torsion out-of-phase loading at $P_{\max }=33 \mathrm{kN}$ and $\mathrm{M}_{\max }=382 \mathrm{Nm}$, phase angle 90 , at 30,500 cycles. $^{54}$ 


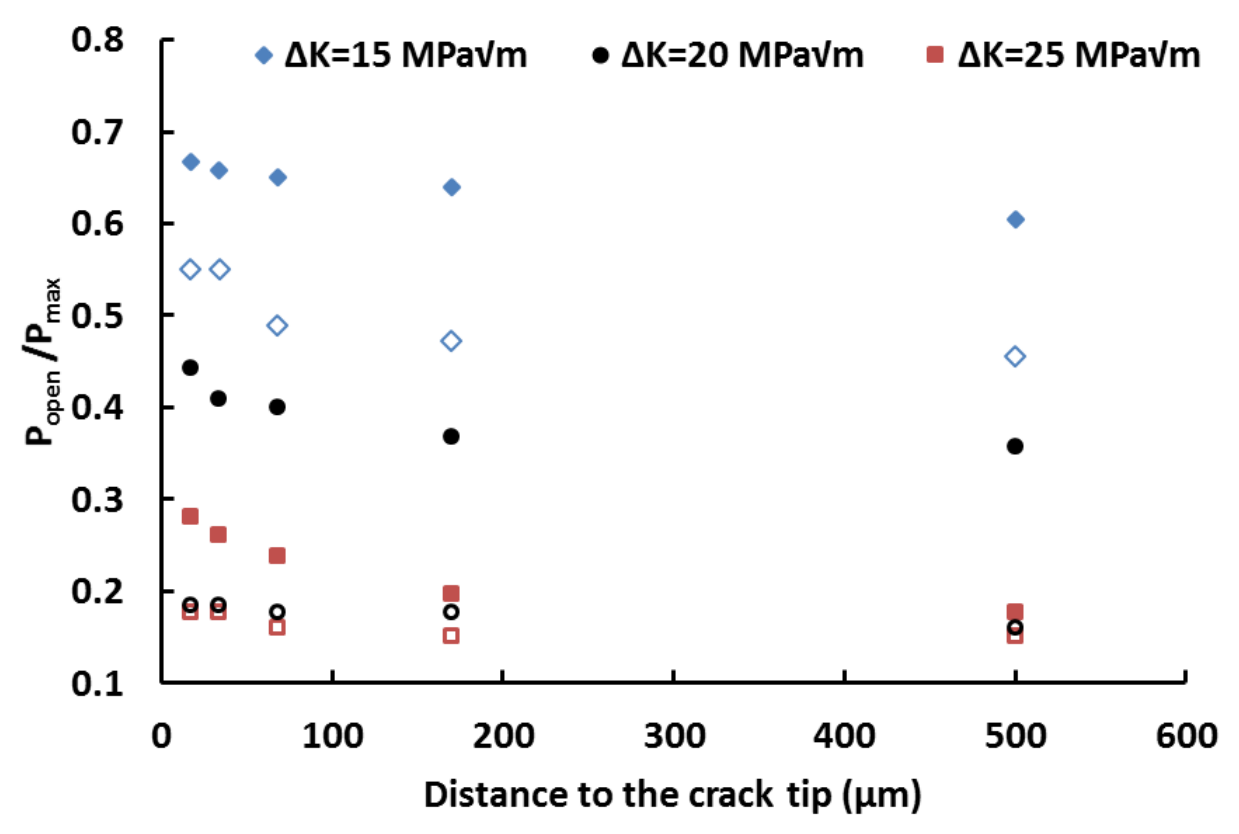

Fig. 9. The crack opening loads measured from DIC data as a function of distance to the crack tip, the effects of load level and the size of the field of view (FOV) (Closed - small FOV; Open - large FOV). ${ }^{59}$ 


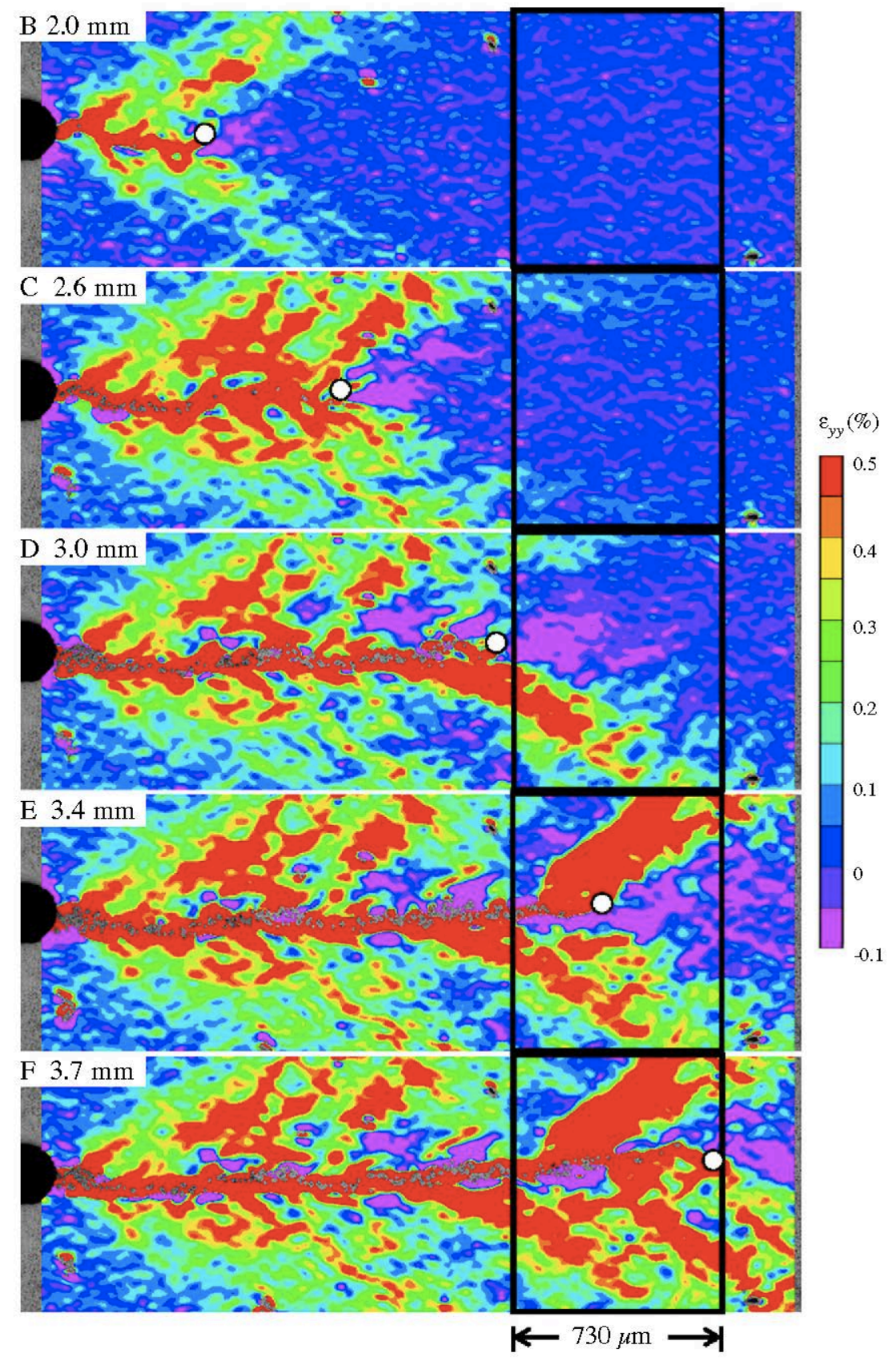

Fig 10. The accumulated plastic strain fields, eyy, recorded at five crack lengths. Plastic strain in the wake of the crack tip is heterogeneous with high and low strain lobes at roughly \pm 40 angles with the crack plane. Black rectangles indicate the area imaged $(0.087 \mathrm{Im} / \mathrm{pix}){ }^{61}$ 
a)
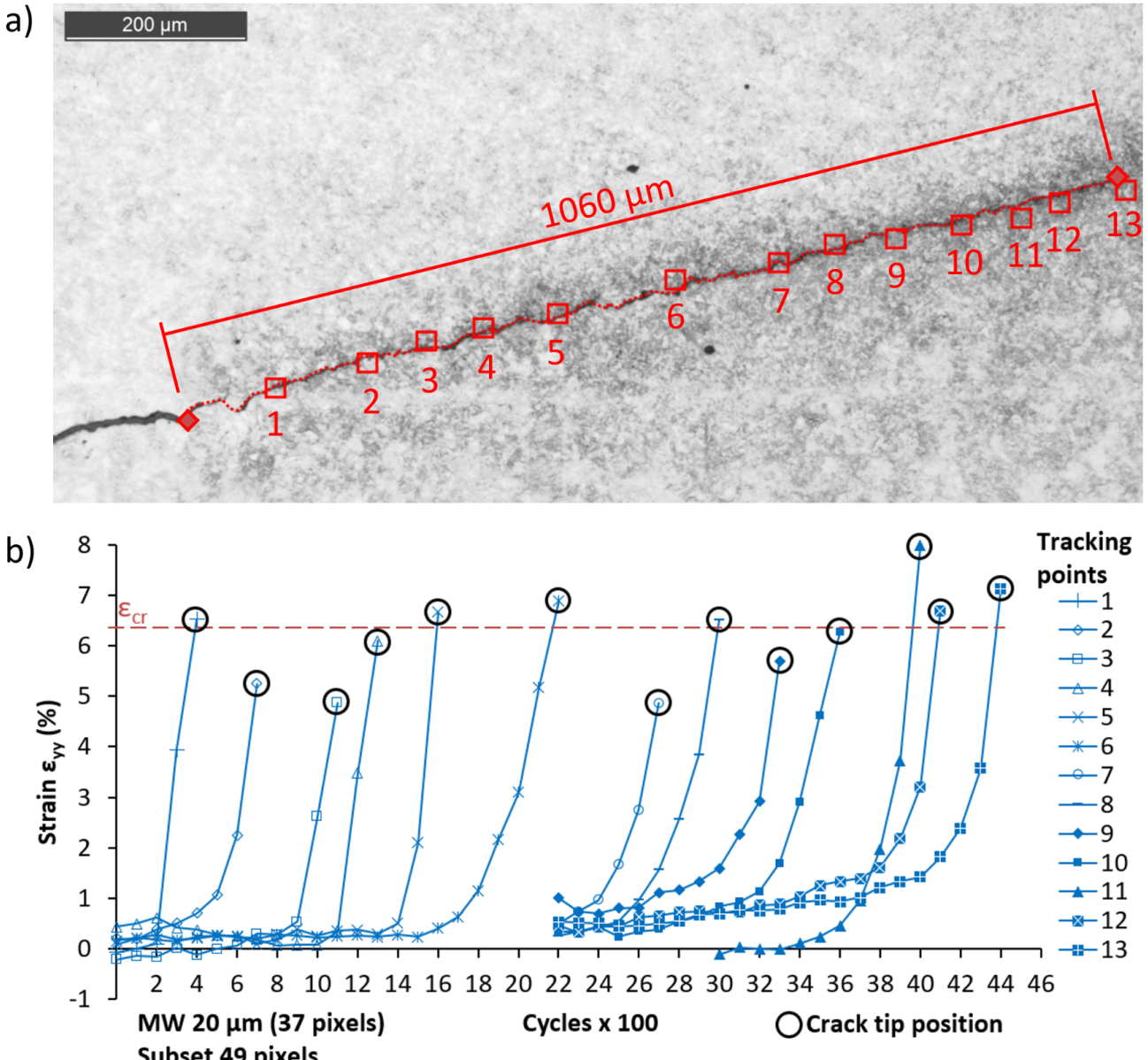

Fig. 11. The normal strains recorded, in situ, as a function of cycles, tracked at selected positions on the crack path (a) at a stress intensity of $\Delta \mathrm{K}=30 \mathrm{MPa} \vee \mathrm{m}$. The black circles indicate the onset strains when the crack tip reached the measurement positions. ${ }^{66}$ 

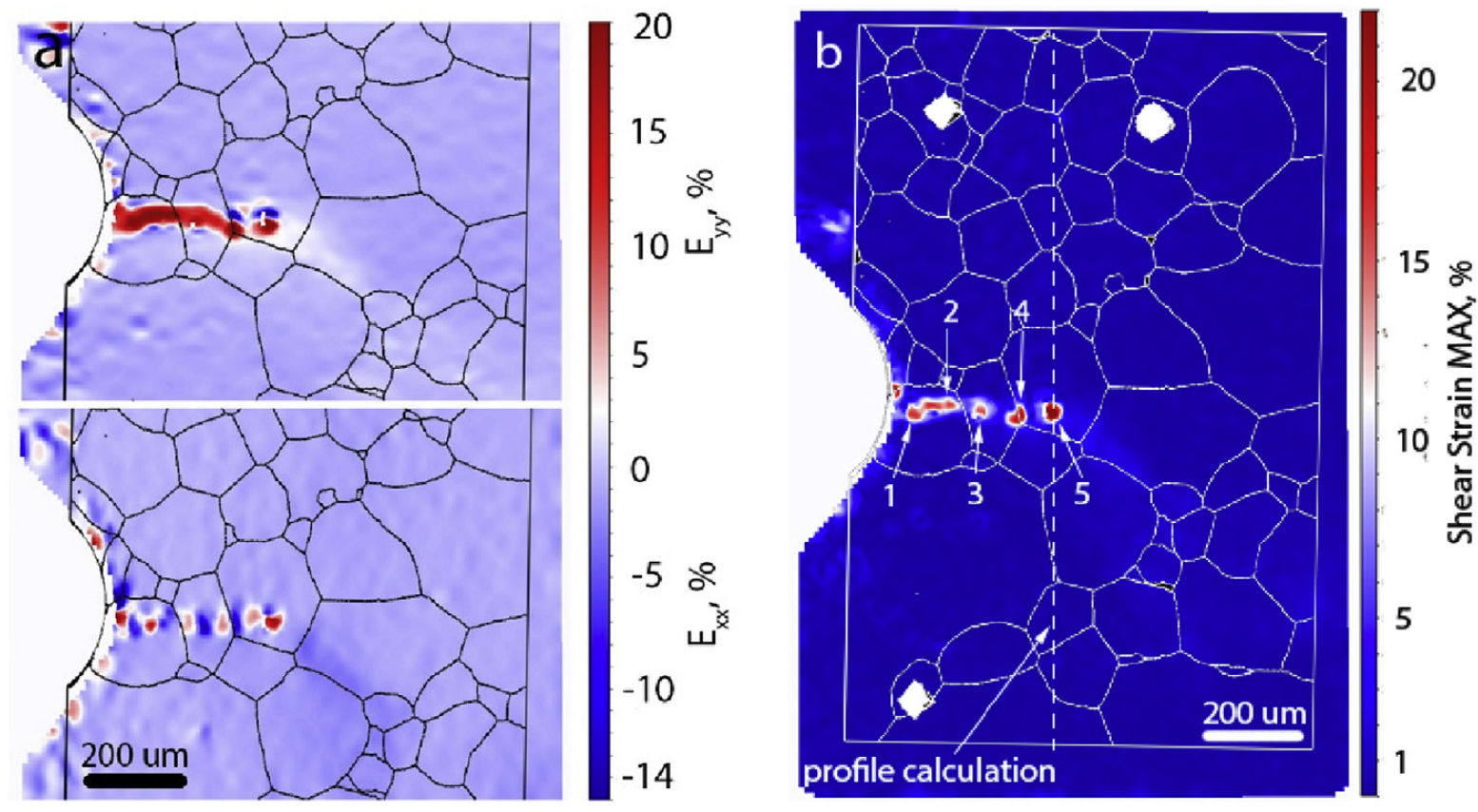

Fig. 12. Strain field of the linear deformations Exx and Eyy (a) and maximum (MAX) shear deformation (b) from DIC during a fatigue test of the ferritic stainless steel specimen, showing strain localization at points $1-5 .^{69}$

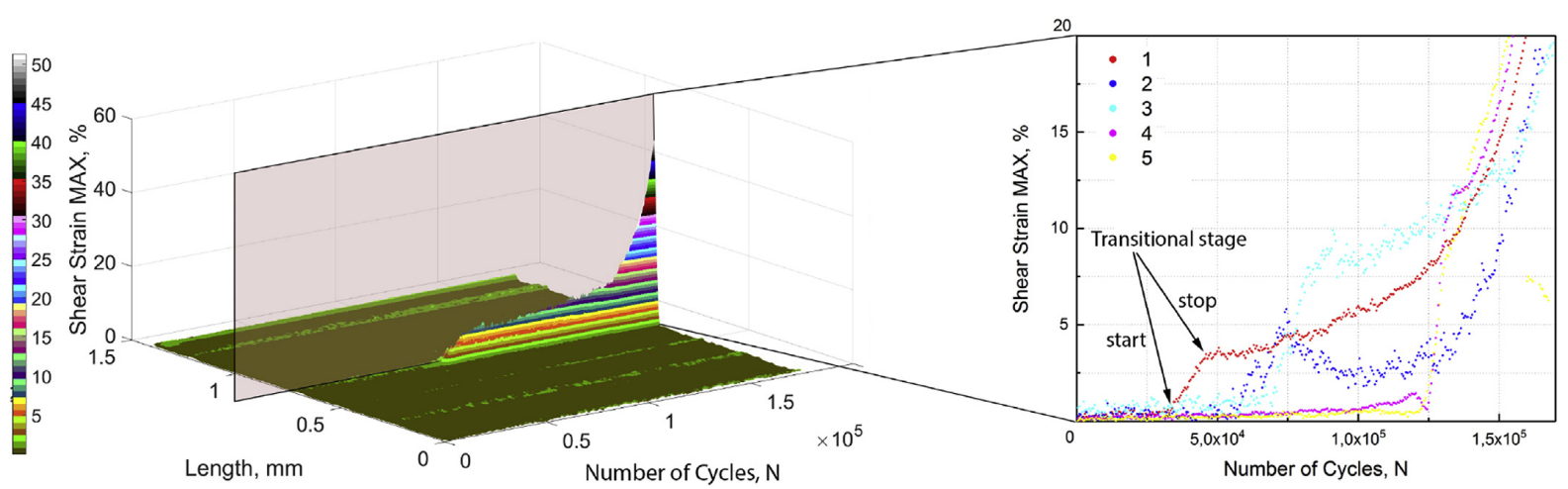

Fig. 13. The shear strain accumulation measured during the fatigue test of a ferritic stainless steel specimen. The maximum shear strain calculated for the strain localization points (1-5) are summarized in the insert. ${ }^{69}$ 